\title{
A Study on the Development of College English Teaching Under the Background of "Double First Class" University Project
}

\author{
*Bing $\mathrm{He}$
}

\author{
School of foreign language, Dalian Jiaotong University, DaLian, China \\ *Corresponding author e-mail: rachelhe2008@163.com
}

\begin{abstract}
The "overall plan for promoting the construction of world-class universities and disciplines" issued by the State Council has made a comprehensive deployment of the "two first-class" construction, bringing not only unprecedented strategic opportunities for Chinese universities, but also putting forward higher requirements for students' international communication ability in the professional field. English teaching, as a kind of language teaching, which helps students to study and research in English, has been paid more and more attention in the reform of College English teaching. How to effectively carry out English teaching and cultivate high-quality applied talents, there is still a lack of clear direction of talent training. While exploring the connotation of first-class universities, first-class disciplines and first-class foreign language disciplines, the aim is to establish a dynamic and systematic curriculum teaching and management mechanism, which will provide some enlightenment for the construction of "double first-class" and the development of foreign language disciplines.
\end{abstract}

Keywords: "double first class" construction, English teaching reform, development strategy

\section{INTRODUCTION}

On November 5, 2015, the State Council issued the overall plan for promoting the construction of world-class universities and disciplines. It is required to adhere to the "four comprehensive" strategic layout and the decisionmaking and deployment of the Party Central Committee and the State Council, adhere to the core of Chinese characteristics and world-class. It is also required to take morality as the foundation and support innovation driven development strategy and serve economic and social development as the guidance. Besides, adhere to the basic principle of "taking the first-class as the goal, discipline as the basis, performance as the lever and reform as the driving force", the plan intends to accelerate the establishment of a number of world-class universities and disciplines. According to the overall plan, by 2020, a number of universities and a number of disciplines in China will enter the world's first-class column, building the world's first-class universities and disciplines, referred to as "double first-class". It is another national strategy in the field of higher education in China after the "211 Project" and "985 Project", which is conducive to improving the comprehensive strength and international competitiveness of China's higher education, and provides a strong pillar for the realization of the "two centenary goals" and the Chinese dream of the great rejuvenation of the Chinese nation. [1] Discipline is the core of university development, which has basic and overall influence on the development of University. First class disciplines promote the development of first-class universities. Without firstclass disciplines, universities cannot become first-class universities, and first-class disciplines are abundant to a certain amount, forming a first-class discipline group. So universities naturally become first-class universities. There are four major problems concerning foreign language disciplines: (1) the overall quality of personnel training is not high; (2) the ability of independent innovation in scientific research is weak, and the influence of scientific research achievements is small; (3) the degree of internationalization is not high, which mainly refers to the internationalization of students, teachers, courses, international cooperation and exchange; (4) the incentive mechanism has not been fully established, and the motivation for teachers to engage in teaching and scientific research has been fully motivated. [2] Based on the "double first class" construction, the following three specific requirements are put forward for College English Curriculum: 1) how to define the curriculum positioning and build a reasonable curriculum system? 2) How to determine teaching objectives and adopt effective teaching methods and evaluation methods? 3) How to improve teachers' ability and cultivate academic English teachers' team? First of all, we need to analyze the connotation of double first-class. It provides theoretical support for the cultivation of university talents with the characteristics of the times under the background of "double first-class". 


\section{CONNOTATION OF FIRST-CLASS DISCIPLINE}

\subsection{The connotation of first-class university}

The first-class university is essentially a research university with American universities as a model. Its typical characteristics are outstanding scientific research (with scientific research achievements recognized by peers and able to promote the knowledge frontier). They have freedom of learning and strong knowledge atmosphere, effective institutional management, adequate facilities and sufficient funds. World class universities involve firstclass students, first-class teachers, first-class academics, first-class resources, first-class management, first-class services, etc., among which students, teachers and academics are common. In contrast, foreign scholars pay more attention to resource facilities and college management, while domestic scholars pay more attention to social services. The world-class universities with Chinese characteristics should have the following conditions: first-class teaching, first-class scientific research, first-class teachers, first-class social services and first-class management. [3]

\subsection{The connotation of first-class discipline}

The first-class discipline should have a strong ability of knowledge dissemination, knowledge production and knowledge application, and this function is two-way, each function is to strengthen the other two functions. The construction of world-class disciplines means to build world-class discipline organizations, improve academic output capacity, and produce world-class academic achievements in personnel training, scientific research, social services and cultural innovation and inheritance. The Chinese standard of world-class disciplines: first-class scholars, first-class student quality, first-class scientific research, first-class academic reputation, first-class social services. Although each of the above points has its own emphasis, they all emphasize such elements as personnel training, scientific research and social services. [4]

\section{CURRICULUM ORIENTATION DRIVEN BY PROFESSIONAL NEEDS}

The key to the reform of Public English teaching lies in the change of curriculum orientation and the adjustment of curriculum system. Based on the past teaching reform practice, we believe that this transformation and adjustment cannot be realized only by the internal strength of the public English teaching department. Only by closely combining the needs of national talent training and the orientation of the school, fully considering the needs of various professional departments for students' English ability, and getting the recognition and support of the school and departments, can the teaching reform be successful. [5] The College English curriculum system should be optimized and integrated reasonably. The curriculum should reflect the local, characteristic and application-oriented features, that is, it should be in line with the local economic and social development needs and talent needs, and it should be combined with the characteristics of the college to cultivate the applicationoriented talents suitable for the social development. At the same time, we should also combine the professional characteristics of our school, let teachers of other majors cooperate with English teachers, and set up professional courses in English according to the actual situation of our school and talent training program, or combine the needs of professional courses to better play the application of English in applied courses.

\section{ABILITY CENTERED ASSESSMENT METHOD}

Scientific testing and evaluation system is an important part of the reform of academic English teaching. In view of the different orientation and source of students, we still need to develop our own academic English test evaluation system. There are also some famous universities in China that have developed school-based College English proficiency tests, but most of them are general English. In order to test the students' Academic English ability and provide objective and real feedback information for the front-line teaching, it is necessary to develop a schoolbased general academic English proficiency test based on Academic English course teaching. Schools need to build a practical teaching system to increase the strength of practical teaching in and out of school, and strive to cultivate students' practical ability. [6] Schools should take various forms of teaching, such as the combination of theory and practice, the combination of in class and out of class. On the basis of cultivating students' solid basic English skills, schools should open up "the first classroom" and "the second classroom". Only by activating the role of student associations, subject competitions, science and technology and culture activities, can students' interest in learning and practicing English be stimulated. Therefore, "Double first-class" applicationoriented teaching system which combines knowledge, ability and practice can be well established.

\section{TEAM BUILDING OF COLLEGE ENGLISH TEACHERS}

The guarantee of the success of English teaching reform lies in the transformation and growth of Public English teachers. Teachers need to change their ideas and understanding (from negative resistance to positive response), update their teaching objectives (from improving their English level to improving their ability to 
communicate effectively within and outside the discipline), and actively explore new teaching methods (from traditional teaching to language and corpus assisted teaching). Otherwise, academic English courses will not achieve the expected goals, and will not be able to help the school's "double learning" First class construction. [7] Teachers' professional skills can be improved by actively introducing a group of teachers with the background of enterprise industry and actively sending young teachers to the enterprise industry to practice and take part-time jobs. The school should also carry out the collective preparation of English teaching, strengthen the discussion and sharing of experience; regularly organize English teachers to participate in research, domestic and foreign academic exchange meetings, etc., to learn the latest cutting-edge English knowledge and academic achievements, which is conducive to promoting the improvement of teachers' teaching and research level.

\section{THE DEVELOPMENT STRATEGY OF ENGLISH TEACHING IN FIRST-CLASS UNIVERSITIES}

\subsection{First class personnel training}

Under the background of "double first-class", the cultivation of top-notch innovative talents has become an important task of University and discipline construction. The newly revised higher education law in 2015 clearly points out that colleges and universities should focus on personnel training and carry out teaching, scientific research and social services. In terms of talent types, it is not only necessary to train single talents in language and literature, translation and business English, but also cutting-edge talents in various fields, international organization talents, non-general language talents, outstanding young talents coming to China, national and regional research talents. Colleges and universities should set up English teaching and training bases according to their own orientation, and train and select compound talents to meet the national strategic development.

With the continuous development of science and technology and the extensive use of multimedia and Internet, the multimodality of meaning expression and information transmission has become the normal of human life and communication. "Double first-class" strategy puts forward higher requirements for the cultivation of international talents. In the aspect of teaching reform, we should advocate the idea of internationalization and informatization. First of all, we should set up interdisciplinary courses, international courses, experiential courses, innovation and entrepreneurship courses. Work closely with relevant overseas departments, set up overseas practice bases. We can carry out exchange students, interns and other projects to expand students' horizons and improve their ability to solve practical problems. In the reform of education and teaching, it is also very important to cultivate students' sense of responsibility, mission and core values. Besides, we try to learn important current affairs documents in foreign languages, excavate the essence of Chinese excellent traditional culture, and create a strong educational environment.

\subsection{First class academic research}

From the content and perspective of the research, at present, the focus of domestic research is on the cultivation of multiple reading and writing ability, mainly introducing the introduction and practical application; the theoretical basis of the research is also diversified, and the research objects basically cover the main elements of English teaching, showing diversified characteristics; from the perspective of research methods, the proportion of empirical research is increasing.

The research contents are mostly linguistic, literary, translation, cultural and other ontological studies. There is less interdisciplinary application research on the strategic needs of the country. There are more applications for research systems and research methods in Europe and America, and less on local innovation research. The firstclass foreign language academic research means that on the one hand, it is necessary to conduct research in the frontier field of foreign language and literature to lead the development trend; on the other hand, it is necessary to conduct comparative research, translation research and localization research based on the current situation of foreign language education and teaching, combined with the cultural characteristics of Chinese language and literature, find new problems and trends, put forward new ideas and build new theories, and recommend research to the international academic community Research results. In addition, we need to meet the needs of the country and society, strengthen multilingual and interdisciplinary regional and national studies, tell Chinese stories from an international perspective, and promote people to people and cultural exchanges between China and foreign countries. In terms of research and evaluation, at present, foreign language disciplines in Colleges and universities conform to the international academic mainstream, with SSCI, a \& HCI, CSSCI Although this practice has its merits, it should also consider different achievement forms such as monograph, research report, consultation report, curriculum, textbook, translation, etc., avoid the simple bean type examination, implement representative achievement system, and emphasize the social application and influence of achievements.

All in all, the implementation strategy is carried out from five aspects: 1) leadership demonstration. Take the lead to explore teaching methods and lead teachers to improve their academic English teaching skills. 2) Strengthen incentives. Those with outstanding contributions will be recommended preferentially when applying for professional titles and studying abroad. 3) Encourage going out. Send backbone teachers to participate in all kinds of domestic academic English teacher training, 
[5] Luo Ting, Yin Hong. A study on the curriculum of English major in Local Universities under the background of "double first class" [J]. Modern trade industry, 2018,39 (02): 178-179 [6] Yang Yinghua. On the reform of English Teaching in Western Universities from the perspective of "double first class" university construction [J]. Journal of Guizhou Normal University, 2017,33 (11): 72-75

[7] Wang Jingting, Liu Bao. Research on applicationoriented personnel training mode under the background of "double first class" [J]. Microcomputer application, 2018,34 (10): 26-33

\section{CONCLUSION}

In a word, under the background of "double first-class" construction, English teaching reform in Colleges and universities cannot be accomplished overnight. It needs a long time to improve and perfect, and it needs to continue to vigorously carry out English teaching reform and practice. The development of first-class universities, firstclass disciplines and first-class foreign language disciplines needs more emphasis on personnel training, academic research, faculty and social services as the key points of discipline construction, and discipline management provides corresponding guarantee and support. With the integration of educational technology and curriculum as the driving force, we can provide various channels for students to obtain information, perceive information and transmit information, so as to promote the traditional classroom reform of College English, and finally achieve the goal of cultivating firstclass students with international competitiveness to meet the challenges of the national "double first-class" construction.

\section{REFERENCES}

[1] The State Council issued the overall plan for promoting the construction of world-class universities and disciplines [J]. University (Research Edition), 2015, 11:98

[2] Peng Qinglong. On the new trend of subject evaluation and the new path of connotation construction of foreign language subject [J]. Foreign language circle, 2016, (3): 34-41.

[3] Liu Ji'an, Feng Xie Lin. main characteristics and construction strategies of world-class universities [n]. China Youth Daily, March 25, 2016 (02)

[4] Liu Jinqiu. The construction of world-class universities from the perspective of national innovation system -- Taking Peking University as an example [J] Beijing education, 2016 (3): 12-15 